\title{
TRACE INTERPOLATION WITH Partial CRS-Stacks
}

\section{BACHELORTHESIS}

Jesper Sören Dramsch ${ }^{1}$

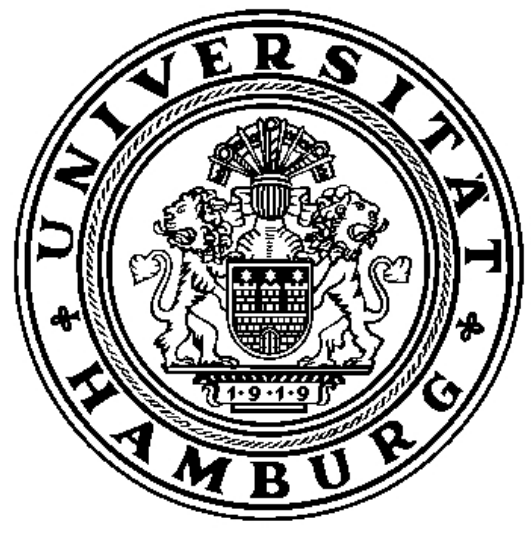

Institute of Geophysics

University of Hamburg

August 2010

1 'jesper at dramsch.net' 


\section{Abstract}

Die folgende Bachelorarbeit wurde in englischer Sprache verfasst und vorgelegt.

Der folgende Abstract ist in Deutsch und Englisch verfasst, um den geneigten Leser einen Einstieg in diese Arbeit zu erleichtern.

\section{Deutsch}

In dieser Bachelorarbeit untersuche ich seismische Spurinterpolierung, Datenregularisierung und Extrapolierung unter Verwendung des partial CRS stack. Dem zugrundeliegenden synthetischen Datensatz füge ich Lücken hinzu und bereite ihn für den Extrapolierungsprozess vor. Ich wähle die Lücken willkürlich im mid-offset Bereich und gezielt im Near-offset. Anschließend vergleiche ich die Interpolierungsergebnisse mit den entfernten seismischen Spuren, untersuche den Datenregularisierungsprozess und analysiere die extrapolierten Spuren.

Die Interpolierung liefert äußerst zuverlässige Ergebnisse, was Einsatzzeiten und die Erhaltung des Frequenzbandes betrifft. Besonders die Einsatzzeiten im Near-offset wurden mit einer minimalen Abweichung berechnet. Allerdings lässt sich auf einigen Spuren niederenergetisches Rauschen im Frequenzband erkennen, darüber hinaus wurden die Frequenzen zuverlässig interpoliert. Die Ergebnisse zeigen einen kontinuierlichen Interpolierungsfehler der direkten Welle auf. Denn die direkte Welle mit linearem Move-out lässt sich nicht durch eine hyperbolische Laufzeitkurve annähern.

Datenregularisierung stellt Interpolierung in regelmäßigen Intervallen dar. Diese Intervalle lassen sich sehr genau definieren und liefern somit entsprechend der Interpolierung zuverlässige Ergebnisse.

Die Extrapolierung von Daten stellt eine Herausforderung an den partial CRS Algorithmus dar, da die Fresnelzone im Untergrund physikalische Grenzen der partial CRS Aperturen definiert. In dieser Arbeit habe ich die Extrapolation für mehr als das doppelte dieser Grenzen 
berechnet. Dementsprechend erwarte ich Artefakte in der Extrapolierung, wie Amplitudenverstärkung und Signalspaltung als Resonanzeffekte. Zu einem gewissen Teil wurden diese Erwartungen auch erfüllt, dass Amplituden sich aufschaukeln, verschmieren und es zu Aufspaltung von Signalen kommt. Diese Artefakte treten bei Offsets über dem 1,5-fachen der Fresnelzone auf. Trotzdem liefern die Ergebnisse der Extrapolierung eine zuverlässige Fortsetzung der Reflexionen, diese werden ab besagter Grenze von den Artefakten überlagert. Aus diesem Grund sollte man die Grenzen der Extrapolierung einhalten, um seine Ergebnisse nicht zu verfälschen.

Zusammenfassend validiere ich in dieser Arbeit den seismischen Interpolierungs- und Datenregularisierungsprozess des partial CRS stack und zeige Grenzen der Extrapolierung auf.

\section{English}

This bachelor thesis is about seismic trace interpolation, data regularization and extrapolation using partial CRS stacks. I edit the underlying synthetic data record to create sparse data and prepare for extrapolation. The gaps appear randomly in mid-offset and specifically in near-offset. Subsequently, I compare the results of the interpolation with the traces I deleted from the record, examine data regularization and analyze the extrapolation.

The interpolation process preserves arrival times and frequencies very well. Especially the arrival times in near-offset are within minimum tolerance. However some trace contain lowintensity noise over the entire frequency bandwidth. The results show an interpolation error for the direct wave. This error occurs because the linear move-out of the direct wave cannot be approximated by the hyperbolic approach of the partial CRS stack.

Data regularization is interpolation for equally spaced intervals. These intervals can be defined precisely and therefore hold the accuracy of the interpolation process.

Extrapolation issues a challenge to the partial CRS algorithm. The Fresnel zone defines physical boundaries for the partial CRS apertures. I calculated the extrapolation for more than double of these limitations. Thus, I expect extrapolation artifacts such as amplitude escalation and signal splitting. These expectations are answered by amplitude escalation, smearing and signal splitting, appearing at 1.5 times the Fresnel zone. Nevertheless, extrapolation supplies a reliable extension of the reflection events. For the sake of extrapolation artifacts limitations by the Fresnel zone ought not be breached.

In conclusion, I validate seismic trace interpolation and data regularization processes of the partial CRS stack and I point out boundaries of the extrapolation process

ii 


\section{Contents}

1. Introduction 3

2. Theoretical Background 5

2.1. Common Reflection Surface Stack . . . . . . . . . . . . . . . . . . . . 5

2.1.1. The algorithm ................... . . . 6

2.2. Partial CRS Stack . . . . . . . . . . . . . . . . . . . . . . . . . . . 8

3. Sigsbee Data Record 9

3.1. Sparse data . . . . . . . . . . . . . . . . . . . . . . . 9

4. CRS supergathers 11

4.1. Trace Interpolation . . . . . . . . . . . . . . . . . . . . . . . . . . . 13

4.2. Data regularization . . . . . . . . . . . . . . . . . . . . . . . . . . . . . 19

4.3. Extrapolation . . . . . . . . . . . . . . . . . . . . . . . 19

5. Conclusion and Outlook 25

A. Acknowledgements I

B. Amplitude Spectra III

C. Bibliography VII

D. List of Figures IX 



\section{Introduction}

Many fields of work benefit from a sufficiently accurate image of the subsurface.

Providing this, many geophysical methods have been developed for different specialized tasks. In reflection seismics we use an indirect measurement of elastic wave propagation in the subsurface. Seismic energy in form of elastic waves is deployed into the underground. This energy will spread according to Fermat's principle. Geologic structures in the underground induce a change in elastic parameters and cause the seismic energy to be refracted, reflected and transmitted. Energy returning to the free surface is being measured using geophones in land seismics and hydrophones in marine seismics. Data acquisition will always consist of several seismic experiments, to collect redundant information.

The data collected must be processed to obtain information about the underground. Redundant data is acquired, to improve the signal-to-noise ratio (SNR). These traces will be stacked to interpolate the geophysically impossible zero-offset (ZO) trace (cf. Gajewski [2010]). This improves the SNR by the square root of the contributing traces, if the noise is non-coherent.

A conventional method to create a ZO-section, consisting of several ZO-traces, is the common-midpoint stack (CMP). For this method a migrating profile is resorted from a common-shot gather to gathers consisting of shots with coinciding midpoint between shotpoint and geophone. These traces are corrected by traveltime and them summed up in the corresponding midpoint trace.

Since we can improve on the signal-to-noise ratio by increasing the contributing traces but we are limited on spreading the acquisition geometry, we need to develop a way to interpolate between additional traces from neighbouring CMPs.

The Common Reflection Surface (CRS) stacking method introduced by Müller [1999], uses a multi-parameter approach. Instead of using only the common-offset-coordinate we additionally use the midpoint-displacement. The surface generated by these coordinates approximates the local curvature of the reflector in the common reflection point (CRP).

The partial CRS method (Baykulov [2009]) is derived from the conventional CRS stack. The 
common reflection point is calculated over a window spanned by the midpoint-displacement coordinate and a limited number of contributing half-offset traces. This calculated trace is saved for every half-offset coordinate. This powerful approach improves the SNR and provides the ability to interpolate traces.

First, I will use the CRS approach on a synthetic data record to interpolate traces, which previously were deleted from the shot-gather. I compare the deleted traces to the interpolated traces and analyze the improvement of the SNR by this routine. Thus, I analyze data regularization and extrapolation with partial CRS stacks. This extrapolation algorithm has limitations with respect to the size of Fresnel zone. These will be unveiled depending on the CRS parameters set.

This thesis will be structured as follows. After this introduction, in chapter 2 I will provide the theoretical background to the CRS stack and partial CRS stacks. I present the data record in chapter 3, which will be used to create a partial CRS supergather in chapter 4 . In section 4.1 I use this supergather to show the interpolation technique of partial CRS stacks. Then this data record will find further use in section 4.2 to show the ability of data regularization and in section $4.3 \mathrm{I}$ investigate limitations of the extrapolation process. In chapter 5 I conclude this thesis and give an outlook for interesting future research topics. In the appendix are the acknowledgments, the declaration of academic honesty ("Selbstständigkeitserklärung"), amplitude spectra evacuated from chapter 4 and the references. 


\section{Theoretical Background}

This chapter reviews the theoretical background to this thesis.

I will present the Common Reflection Surface stack as well as the partial CRS stack and its underlying physics of the CRS algorithm and its parameters.

\subsection{Common Reflection Surface Stack}

The Common Reflection Surface stack is a kinematic multi-parameter seismic processing approach. The CRS method approximates the local curvature of a reflector element. This surface is spanned by the half offset, also used for conventional common midpoint stacks and the domain of the midpoint displacement. The midpoint displacement coordinate contributes neighboring CMP gathers to the interpolated trace, raising the SNR of a resulting trace. The stacking-process over the CRS surface is visualized in Figure 2.1. It shows the 2Dstacking-approach in the midpoint $\mathbf{m}$, half-offset $\mathbf{h}$ and time $\mathbf{t}$ domain. The blue line are the common-offset-gathers. A conventional CMP-Stack would be processed along the magenta line. The red lines show the midpoint displacement corresponding to the Normal-wave on the subsurface reflector-segment. The CRS-stack takes place along the green surface. The result is assigned to the point $P_{0}$ (cf. Baykulov [2009]) The partial CRS stack (cf. section 2.2) is executed over the surface spanned by the red lines and then is written into the according offset coordinate. 


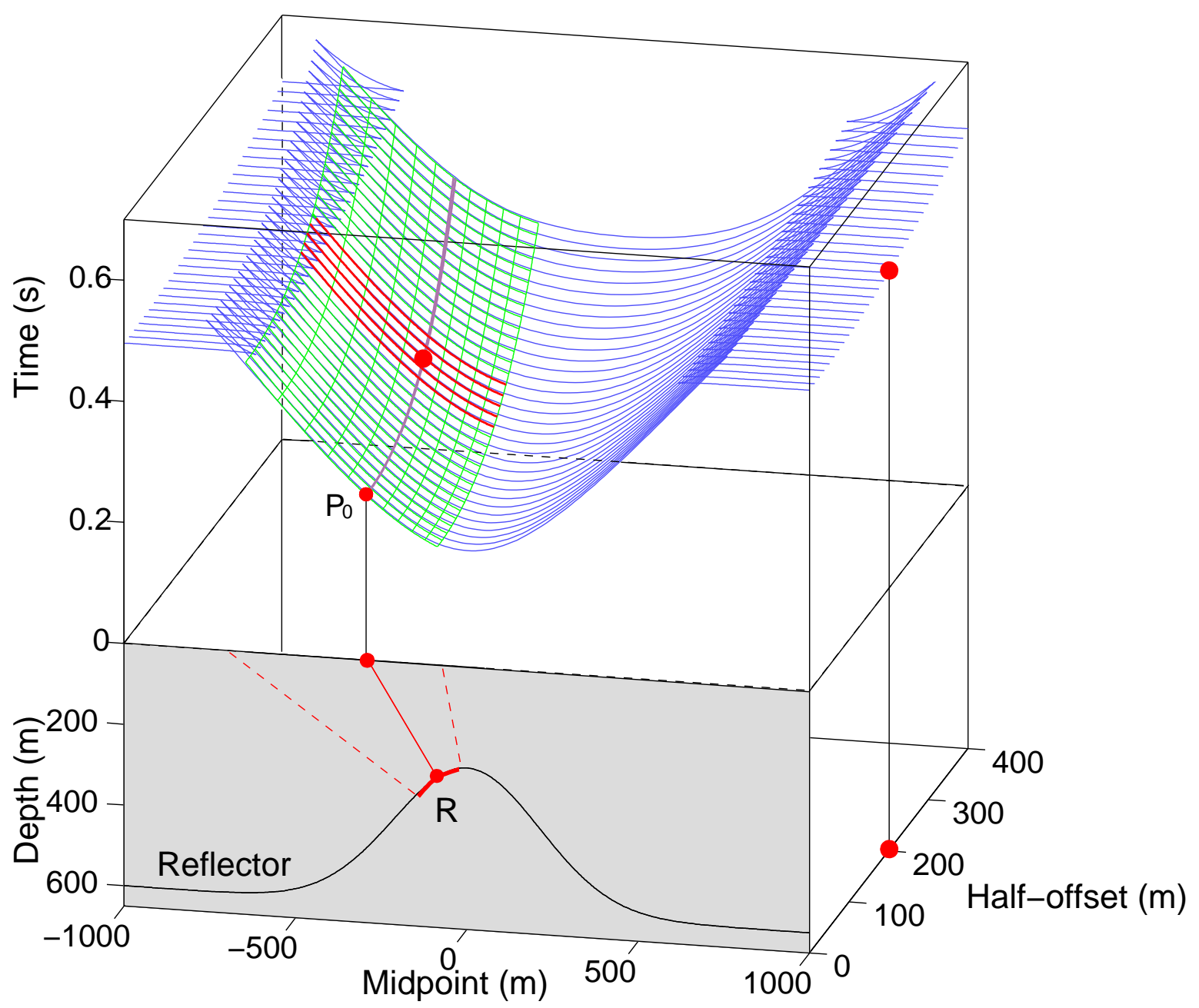

Figure 2.1.: The CRS stacking surface approximates the curvature of the reflector in the underground in midpoint displacement, half-offset and time domain. For a more detailed explanation see section 2.1 (cf. Baykulov [2009])

\subsubsection{The algorithm}

Travel time curves can be approximated by e.g., a parabola or a hyperbola. In reflection seismics the more precise hyperbolic approximation is chosen for the CRS stack. The CRS stacking-surface approximates the observed travel times by a second order Taylor-expansion 
and reads as follows:

$t_{C R S}(m, h, P)=\sqrt{\left(t_{0}+\frac{2 \sin \alpha}{v_{0}} \cdot\left(x_{m}-x_{0}\right)\right)^{2}+\frac{2 t_{0} \cos ^{2} \alpha}{v_{0}} \cdot\left(\left(x_{m}-x_{0}\right) \cdot K_{N}+h^{2} \cdot K_{N I P}\right)}$,

where $t_{0}$ is the ZO travel time, $h$ is the half-offset, $\left(x_{m}-x_{0}\right)$ is the midpoint displacement and $P=\left(\alpha, K_{N}, K_{N I P}\right)$ are the kinematic wavefield attributes hereafter referenced to as CRS (stacking) parameters. (cf. Müller [1999], Mann [2002], Baykulov [2009]).

An essential task is to find starting values for these CRS parameters, doing so with a one parameter search for every parameter and subsequently optimizing the entire triplet. These parameters are defined as follows:

- $\alpha$ represents the angle of the seismic wave emerging to the surface.

- The parameters $K_{N}$ and $K_{N I P}$ describe the curvature of two theoretical experiments.

$K_{N}$ describes the Normal-wave with a curvature equal to an exploding reflector experiment, the CRS.

$K_{N I P}$ describes the "Normal Incidence Point"-wave (NIP-wave)

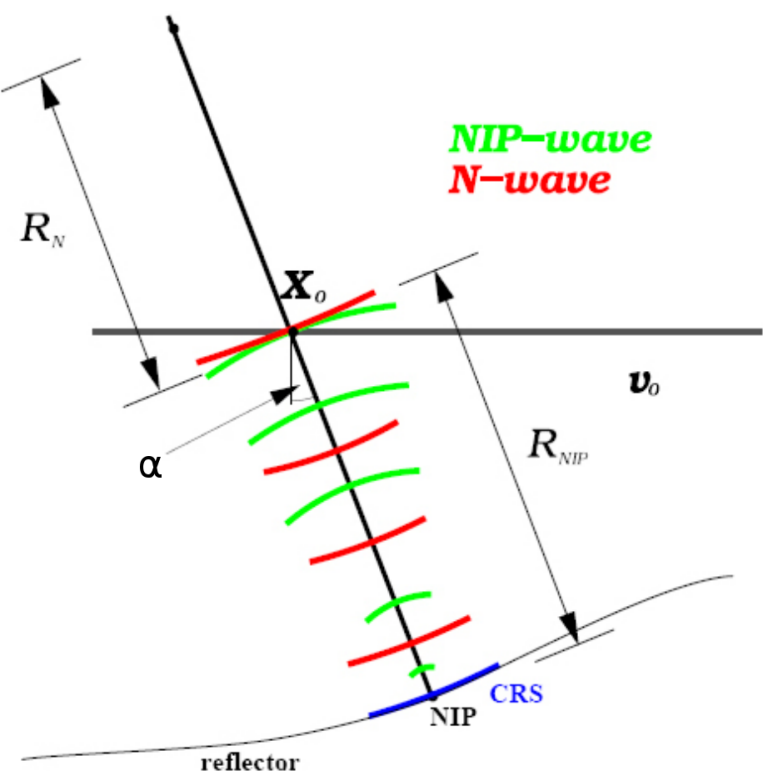

Figure 2.2.: Visualize the CRS parameters introduced in section 2.1 (from Müller [1999], edited) with a curvature normal to the NIP.

These parameters are determined at the registration surface. In figure 2.2 the parameters $R_{N}$ and $R_{N I P}$ are used. They are the radii of the $\mathrm{N}$-wave and the NIP-wave with the following relation to the curvature:

$$
R_{N}=\frac{1}{K_{N}}, R_{N I P}=\frac{1}{K_{N I P}}
$$

Both notations can be found in the literature. The parameters in equation 2.1.1 can be 
substituted to create a more vivid explanation of the CRS stacking algorithm.

$$
t_{C R S}(m, h, P)=\sqrt{\left(t_{0}+A \cdot m\right)^{2}+B \cdot m^{2}+C \cdot h^{2}},
$$

where $t_{0}$ is the ZO travel time, $m$ is the midpoint displacement, $h$ is the half-offset and $P=(A, B, C)$ are the substituted CRS parameters. This relation shows the proximity to the conventional CMP stack e.g., for $m=0$.

All in all, these parameters describe the dip, the curvature and the depth of a reflector segment recorded at the surface. Precise CRS parameters are essential for the calculation of the upcoming partial CRS stack in section 2.2.

\subsection{Partial CRS Stack}

The partial CRS stack was introduced by Baykulov and Gajewski [2009].

This method uses the Common Reflection Surface stack introduced in section 2.1 to calculate a windowed stacking surface around a defined point and time in the offset-midpoint coordinate. This surface coincides locally with the Common Reflection Surface of the initial CRS stack, where the trace in question is created by summation of the windowed surface around this point. It can be repeated automatically for every point within range of the CRS aperture. Out of these generated traces a new partially stacked CRS supergather is generated. In general, the partial common reflection surface is limited by the Fresnel zone in the subsurface.

Supergathers consist of additional traces supplied by neighboring CMPs (cf. chapter4) and they are neither stacked nor NMO-corrected. This provides a wide variety of possibilities for pre-stack data processing. Every single trace consists of a summation of several neighboring traces concluding a significant higher SNR in every offset. The partial CRS stack can be used for trace interpolation of sparse data and data regularization. Under certain prerequisites, like choosing an appropriate stacking aperture, the partial CRS stack can be used for extrapolation of traces, located outside of the prior data record.

The partial CRS stack implemented by Mikhail Baykulov (Baykulov [2009]) uses the CRS parameters calculated by the code Müller [1999] introduced. The user can choose to vary the offset of the traces and interpolate over gaps in the original data.

In chapter 4 I will use this code on the Sigsbee2A data record, presented in chapter 3 to test the interpolation process for validity. 


\section{Sigsbee Data Record}

The Sigsbee2A data record provided by the Subsalt Multiples Attenuation and Reduction Technology Joint Venture (SMAART JV) will be presented in this chapter, as well as the modifications I applied to fit the means of this thesis.

The Sigsbee2A data record is an acoustic synthetic dataset, modeling the geologic setting of the Sigsbee escarpment in the Gulf of Mexico. This provides a noise-free data record with less internal multiples and weaker water bottom reflections. The stratigraphy consists of complex salt structure surrounded by sediment structures. These sediments are traversed by normal and thrust faults. Synclinal structures at the top of the salt structure focus reflected seismic energy and create travel time curves that cannot be approximated by hyperbolas. The data set itself consists of 1996 common midpoint gathers with a maximum offset of $7933 \mathrm{~m}$. The traces contain 1500 samples each trace with a sampling rate of $8 \mathrm{~ms}$. In this thesis I use the first $475 \mathrm{CMPs}$, to limit the runtime of the miscellaneous processing algorithms. The dataset I use was converted into the metric system.

\subsection{Sparse data}

I edited the original synthetic data record to provide sparse data for the interpolation process. In this process I created gaps in near and mid-offset consisting of multiple missing traces. The near-offset gap was chosen to simulate marine data records, with missing data in offset ranges up to $300 \mathrm{~m}$. The mid-offset traces were deleted randomly from the gather. Additionally I expanded the possible offset to facilitate extrapolation beyond the actual offset. In this thesis I use CMP 200 to demonstrate the processes and analyze results. These results are plotted in wiggle trace with variable area-fill of positive amplitudes. 


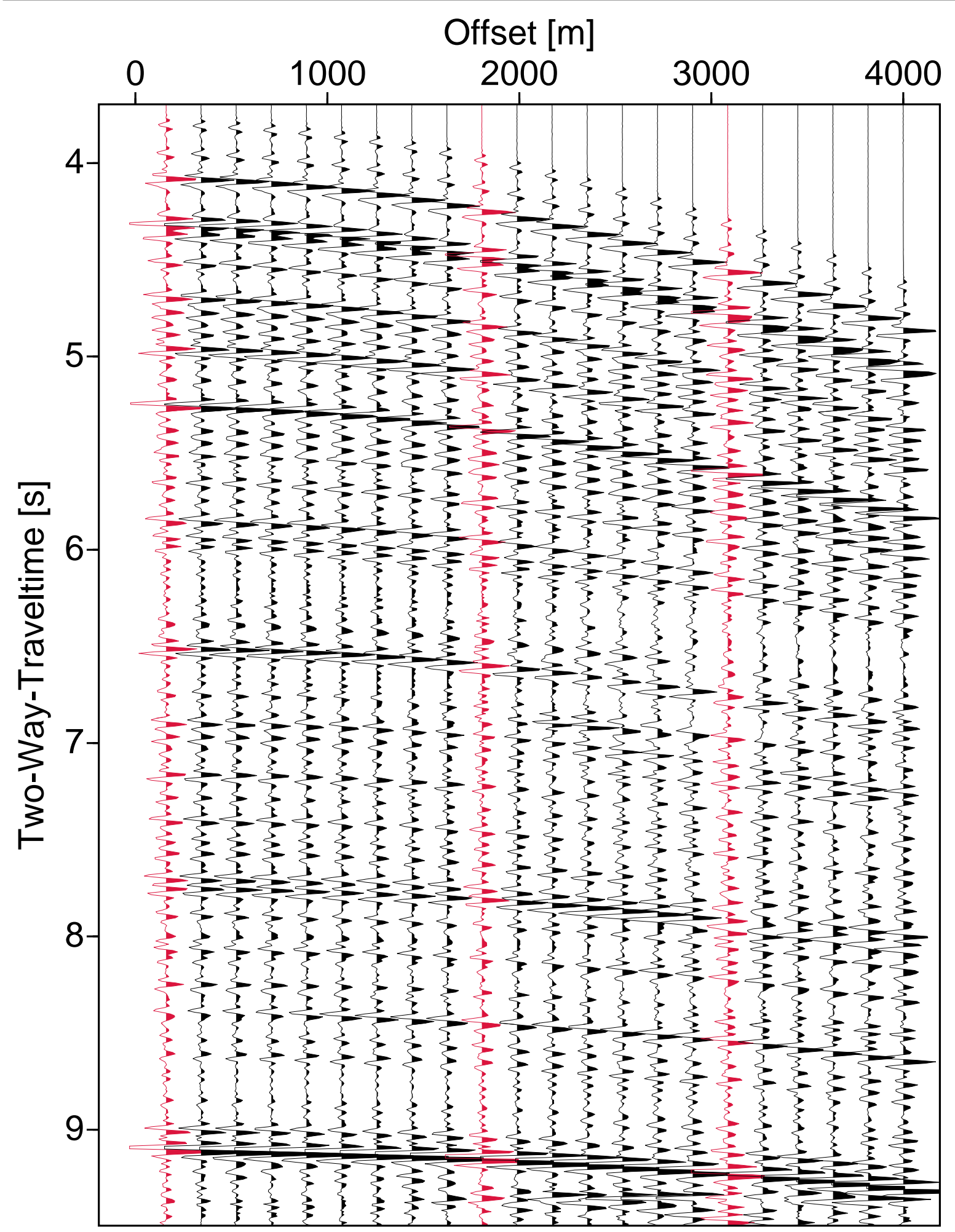

Figure 3.1.: CMP 200 of original data record. Red traces mark data gaps in the sparse data record. 


\section{CRS supergathers}

In this chapter I will analyze the central questions of this thesis and present data to evaluate the interpolation, regularization and extrapolation processes.

As suggested in section 2.2, due to the partial CRS process, supergathers can be created consisting of significantly more traces than the original data record. Due to the approximation of the subsurface reflector segment, any trace in the chosen aperture can be created as a result of the partial stacking process of several hundred contributing traces. Within the following chapter lies the core of this bachelor thesis. I will show the different capabilities of the partial CRS stacking process with respect to inter-, extrapolation and regularization processes. After that, I interpolate over gaps and compare the interpolated traces to the original trace. This will will allow the estimation of the accuracy of the partial CRS process and lead me to the regularization of data and eventually to extrapolation processes, using offset apertures that exceed the physical limitation of the original gathers.

Figure 4.1 shows the regularized, interpolated and extrapolated supergather of the edited sparse data record. I have set the trace spacing to 20 meters. On first sight, one can already perceive the significant increase in trace count. Another improvement is the increase of coherency of the single reflections. In the original data record, between 8 and 8.5 seconds, reflections can vaguely be discovered on the shear eyesight, however, in the supergather these reflections can easily be connected. As we can see, the data was extrapolated over the maximum offset of $4000 \mathrm{~m}$. This once again increases the contributing traces in a stacking process.Nevertheless, the extrapolation process must be applied cautiously, for a change in signal would disturb the result of the stacking process. The results and accuracy of the interpolation process and by association, the regularization are discussed in the following sections, as well as extrapolation. 


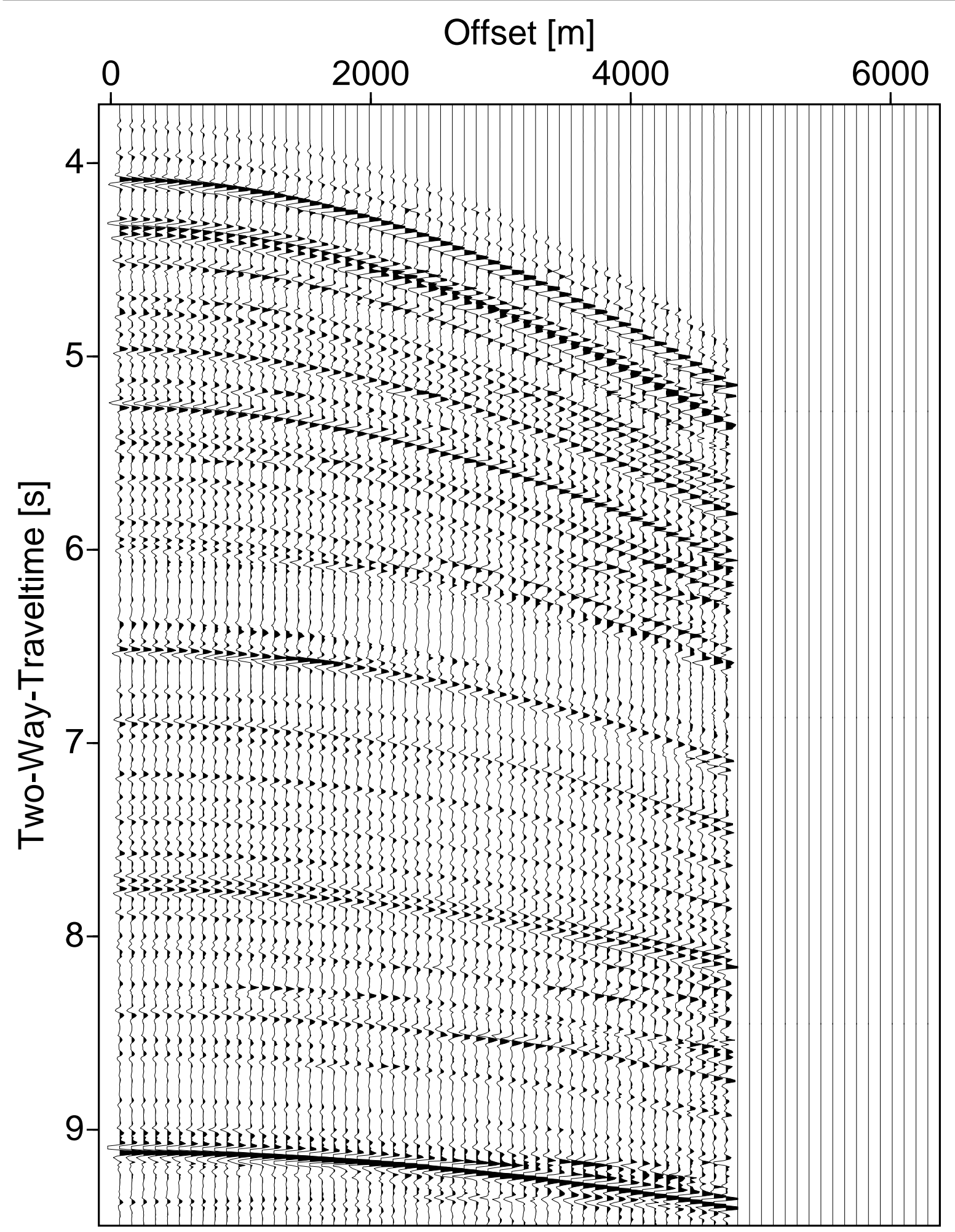

Figure 4.1.: Supergather consisting of data that was interpolated, regularized and extrapolated. 12 


\subsection{Trace Interpolation}

Interpolation of seismic traces has a long history in seismic processing. First approaches using interpolation to create a zero offset trace and subsequently ZO gathers, accomplished geophysics to be vaulted into a new era. Although interpolation processes already had such a great impact on geophysical data analysis, there are more applications in further interpolation processes.

Accurate geophysical data acquisition has a major influence on the stability and reliability of various processing algorithms, especially waveform-based ones, including characteristics like coherence and regularity. These premises can easily be breached, because of broken geophones or varying geophone spacing. Once the geophone spacing gets too large waveformbased processing algorithms encounter aliasing effects. Another problem specific to marine data acquisition originates in missing near offset data. This data is essential for surfacerelated multiple elimination (SRME; cf. Verschuur et al. [1992]). Dümmong et al. [2009] show that in a 2D-medium prediction errors of the SRME have not occurred after partial CRS interpolation. The kinematic approach of the partial CRS stacking technique provides ideal prerequisites to fill sparse data, regularize and even extrapolate data.

\begin{tabular}{|c|c|c|}
\hline \multicolumn{2}{|c|}{ Arrival time [s] } & \\
\hline \hline $\begin{array}{c}\text { Original } \\
\text { data }\end{array}$ & $\begin{array}{c}\text { Interpolated } \\
\text { data }\end{array}$ & $\begin{array}{c}\text { Relative } \\
\text { error }\end{array}$ \\
\hline \hline 3.74326 & 3.74064 & $7,00 \cdot 10^{-4}$ \\
\hline 3.74391 & 3.74296 & $2,54 \cdot 10^{-4}$ \\
\hline 3.74365 & 3.74324 & $1,10 \cdot 10^{-4}$ \\
\hline \hline 3.90492 & 3.91173 & $1,74 \cdot 10^{-3}$ \\
\hline 3.92604 & 3.93138 & $1,36 \cdot 10^{-3}$ \\
\hline 3.94496 & 3.94888 & $9,93 \cdot 10^{-4}$ \\
\hline \hline 4.23032 & 4.23327 & $6,97 \cdot 10^{-4}$ \\
\hline 4.25855 & 4.26295 & $1,03 \cdot 10^{-3}$ \\
\hline
\end{tabular}

Table 4.1.: Comparison of arrival times

Figures 4.2 to the right shows the traces from the original data record, which were deleted, to compare them to the interpolated traces from the supergather in the adjacent picture. Figure 4.2.1 shows the original traces taken from the Sigsbee $2 \mathrm{~A}$ data record. Next to it, figure 4.2.2 shows the result of the interpolation over the data gaps.

On first examination one can already discern the conformity of the traces I present. Nevertheless, one can see that the arrival times of the reflection events, we can perceive the apparently correct placement of the onset. In table $4.1 \mathrm{I}$ itemized the single arrival events. In the near-offset domain the arrival times differ by the order of $10^{-3} \mathrm{~s}$. In mid-offset the absolute error increases to the $10^{-2 n d}$ order. These result in a maximum relative error of $10^{-3}$. 


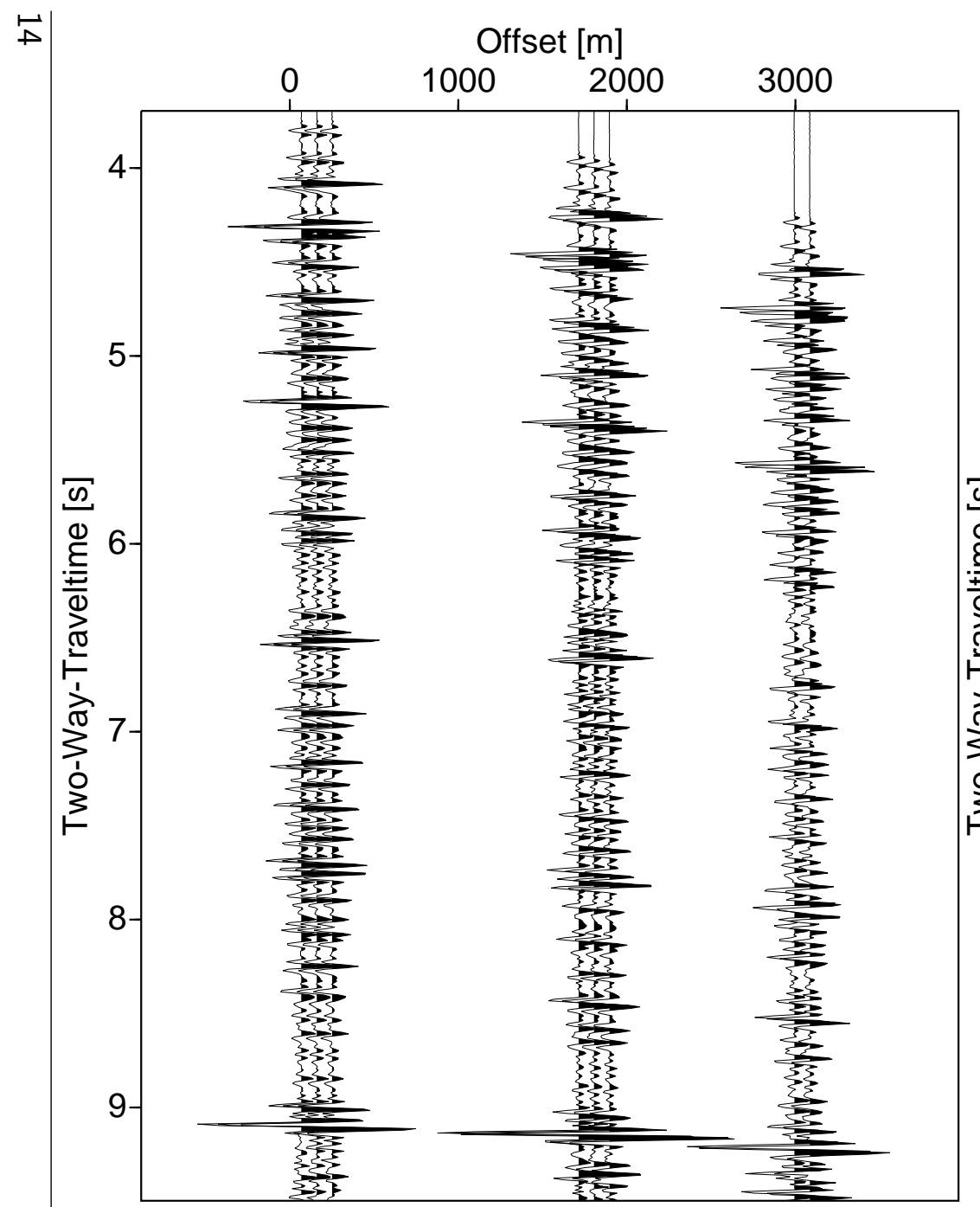

4.2.1: Original traces in CMP 200

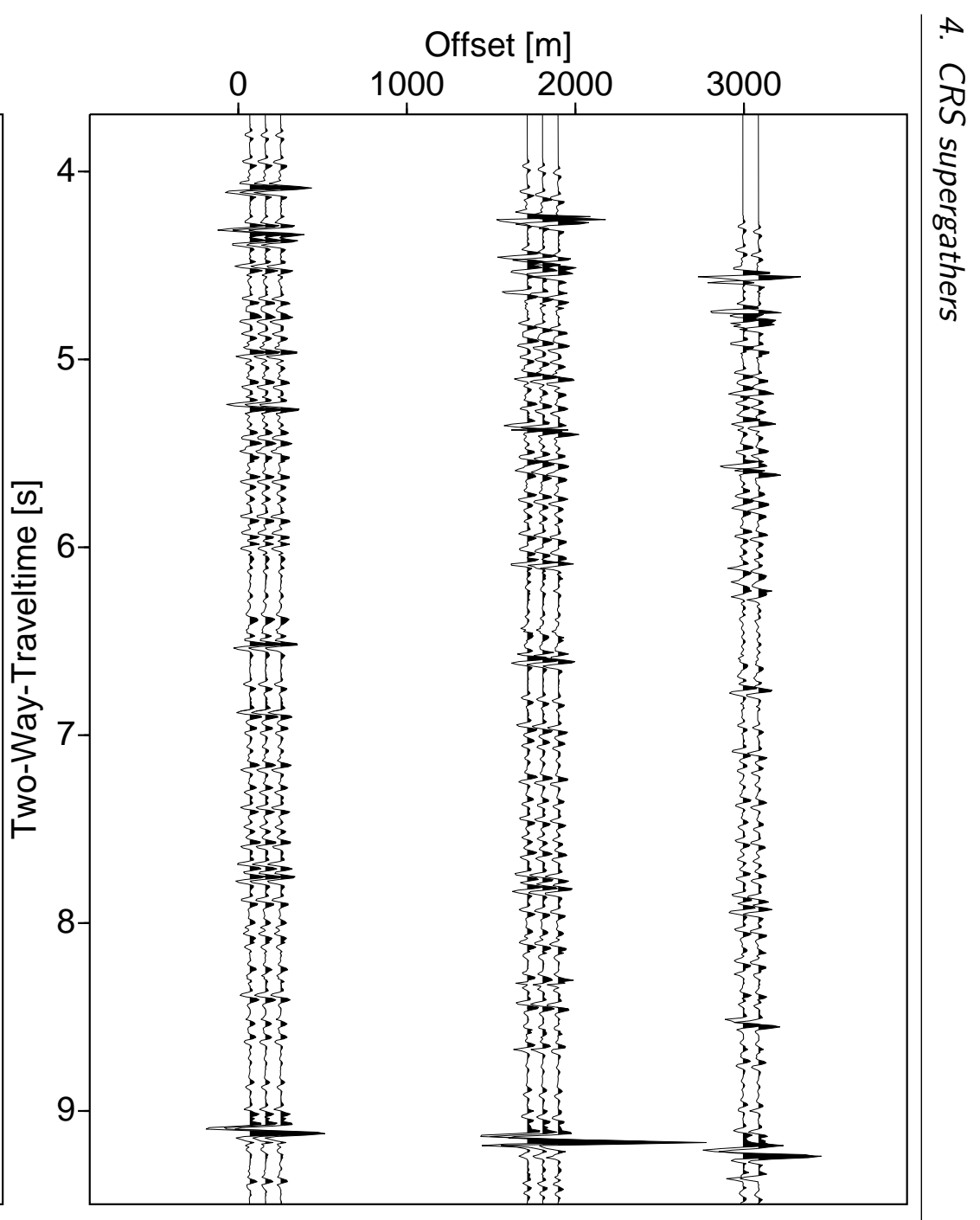

4.2.2: Interpolated traces in CMP 200

Figure 4.2.: Comparison of the interpolated and the original traces 
The direct wave is placed in the right temporal position but has undergone a significant change of the signal form. Viewing the amplitude spectrum including the direct wave shows an interpolation error as well. The explanation lies in the linear move-out of the direct wave. This linearity cannot be reproduced with the hyperbolic approach of the partial CRSalgorithm. This knowledge must be applied by muting or windowing the data, cutting out data that might lead to processing errors.

The single reflection events in figure 4.2.2 appear more discrete than those in figure 4.2.1. There are less minor amplitudes in between the major reflection events. This is interesting because the Sigsbee2A data set is noise-free and still there is an improvement to the overall image of the data. Another difference is an evident diminution of the signals beyond 9.5 second TWT. The traces around $3000 \mathrm{~m}$ offset even draw an almost event-free picture beyond $9.5 \mathrm{~s}$.

The overall image of a consistent interpolation is confirmed by the amplitude spectra of two traces in figure 4.3. The upper two figures 4.3.1 and 4.3.2 show spectra of the interpolated traces at an offset of $68 \mathrm{~m}$ and $1805 \mathrm{~m}$, chosen exemplary as a near-offset and mid-offset trace. The spectra of the matching original traces are presented in the lower figures 4.3.3 and 4.3.4. It strikes that the scales of each offset match in the interpolated and original trace. Additionally the main bandwidth of the traces spans from $5 \mathrm{~Hz}$ to $30 \mathrm{~Hz}$. In the near-offset trace the interpolated spectrum appears smoother than the original spectrum. In the original spectrum we can see four peaks at approximate frequencies of $11 \mathrm{~Hz}, 16 \mathrm{~Hz}$, $20 \mathrm{~Hz}$ and $23 \mathrm{~Hz}$. While in the interpolated spectrum the only peak appearing is at $11 \mathrm{~Hz}$. However, one can spot a frequency drop from $11 \mathrm{~Hz}$ to $13 \mathrm{~Hz}$, which is clearly presented in both spectra. This gap appears in the mid-offset trace spectrum as well. Although, as opposed to the near-offset trace some noise appears in every frequency, visible from $\mathrm{OHz}$ to 5 $\mathrm{Hz}$ and from $30 \mathrm{~Hz}$ on to the end of the bandwidth. In appendix B the amplitude spectra for every trace are presented. The comparison of these spectra leads to the same conclusion including smoothed frequency peaks, low intensity noise and well-interpolated frequency trends. 

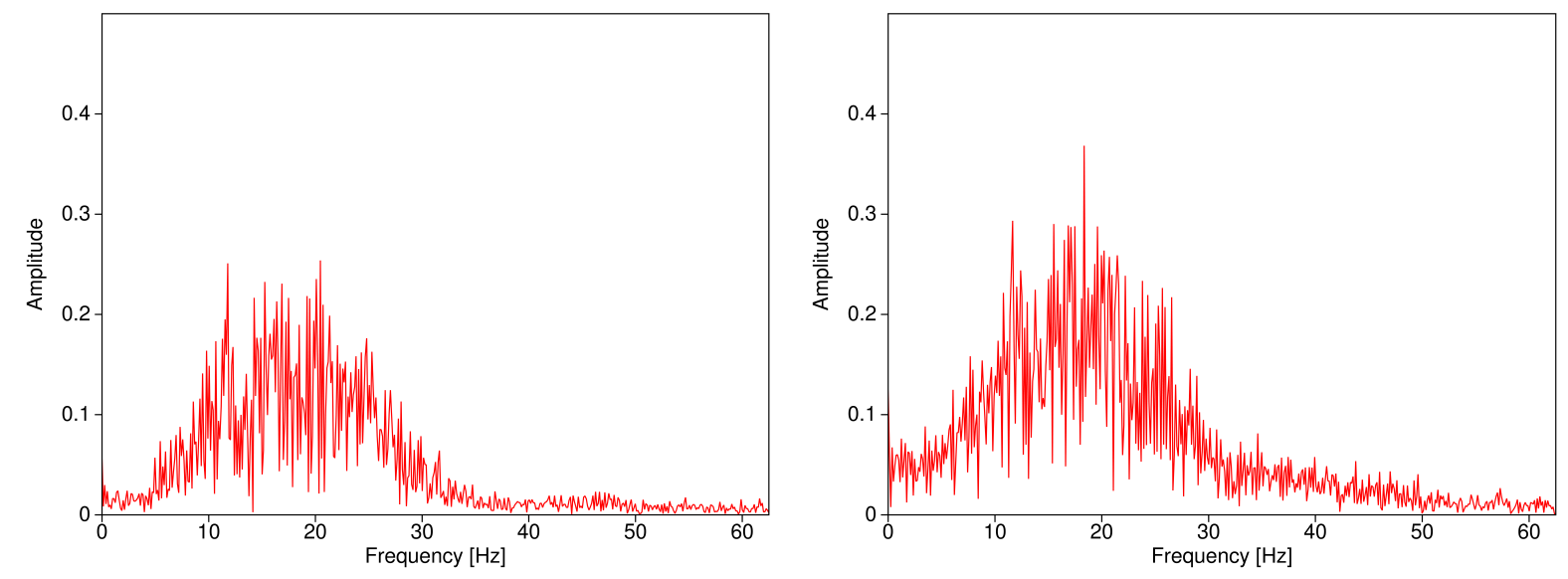

4.3.1: Amplitude spectrum of the interpolated trace at an offset of $68 \mathrm{~m}$

4.3.2: Amplitude spectrum of the interpolated trace at an offset of $1805 \mathrm{~m}$
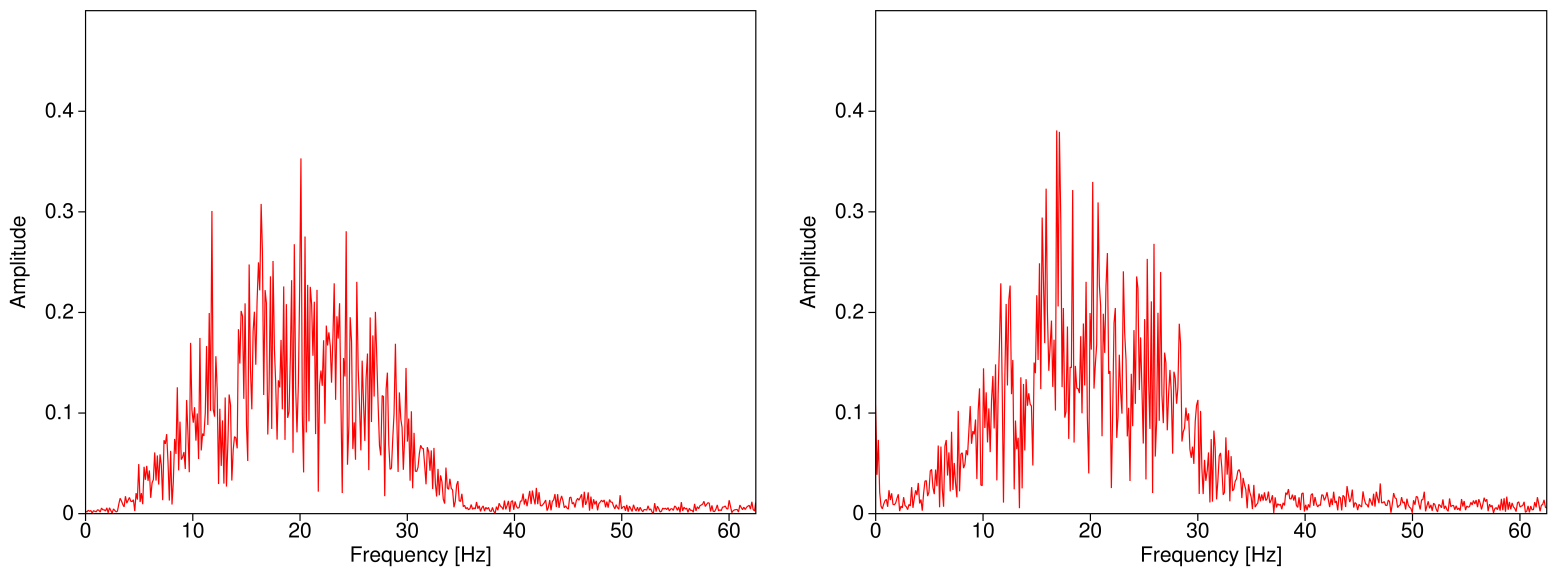

4.3.3: Amplitude spectrum of the original

4.3.4: Amplitude spectrum of the original trace at an offset of $68 \mathrm{~m}$ trace at an offset of $1805 \mathrm{~m}$

Figure 4.3.: Interpolated and original amplitude spectra of two traces at the offset of $68 \mathrm{~m}$ in near offset and $1805 \mathrm{~m}$ in mid-offset (cf. appendix B for spectra of all interpolated traces) 
In figure 4.4 I compare the segments of the original data from 6s TWT to 9.5s TWT with an interpolation over the simulated near-offset gap. In this close ups one can observe the amplitudes of the first three traces of the CMP-gather. In the timespan from $6.0 \mathrm{~s}$ to $6.5 \mathrm{~s}$ the amplitudes are very discrete in the original traces. The according amplitudes in the interpolated traces are smaller, as well as broader. This low intensity amplitude smearing can be observed on the entire interpolated gather.

I marked several events red, which appear to be major reflection events and to some extent, have undergone a change in amplitudes. The first red event at $6.5 \mathrm{~s}$ TWT is an event with very high amplitudes. This event has been interpolated very accurate, as well as next event at $6.9 \mathrm{~s}$ TWT. Whereas the event at $7.2 \mathrm{~s}$ and the event at $7.4 \mathrm{~s}$ show a decrease in intensity and broadening of the signal. The following double amplitude at 7.7s TWT again is interpolated very exact with a slight decrease in intensity. Moving on to the events between $8.2 \mathrm{~s}$ and $8.5 \mathrm{~s}$, the first event has decreased and broadened significantly while the second event was amplified and sharpened. The major double amplitude at 9.0 s has suffered smearing over the first two amplitudes. The first event has experienced the most amplitude smearing, loosing amplitude and attaching to the second event. This second event has also lost amplitude but is still recognizable as a discrete major event. The third amplitude after those red events again has been interpolated very well.

These slight differences marked in figure 4.4 show that major events in near-offset domain are interpolated very well, with minimal changes in amplitude. Although the CRS stack is a kinematic approach the amplitudes have been preserved very well. Minor events are victim to low intensity amplitude smearing, forfeiting discreteness in the interpolated traces. On the other hand, travel times are well preserved, placing major reflection events correctly. 


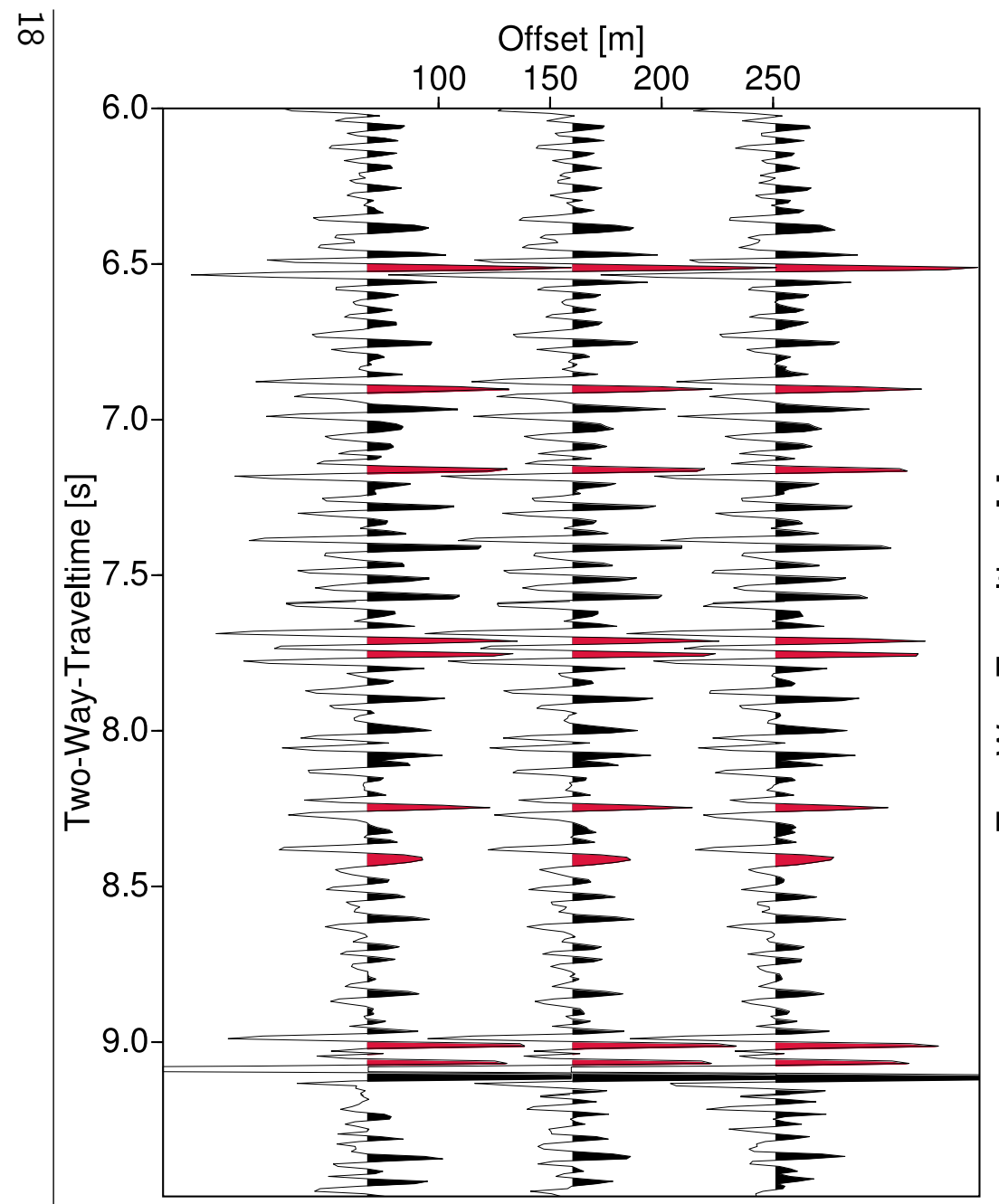

4.4.1: Segment of original near-offset data

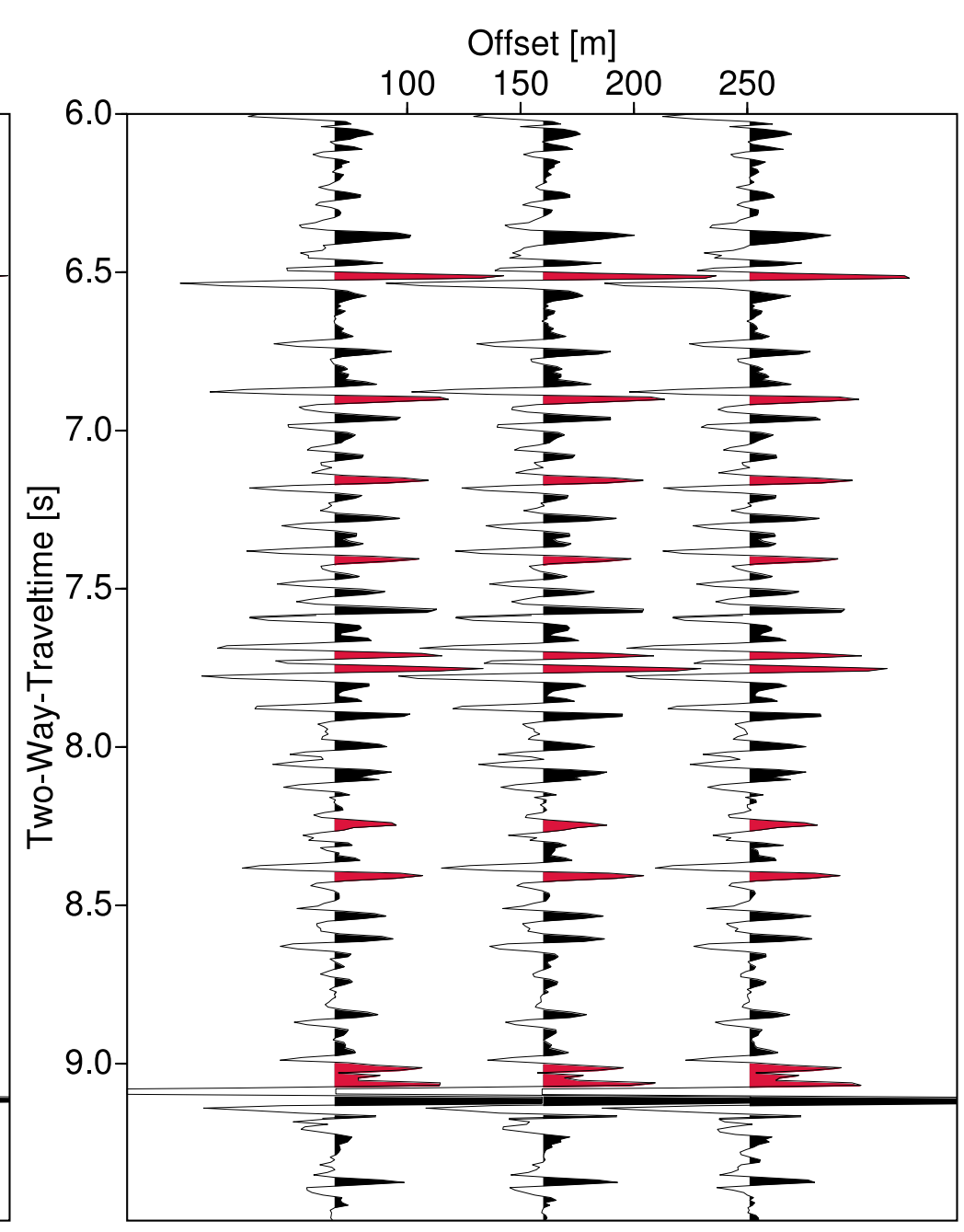

4.4.2: Segment of interpolated near-offset data

Figure 4.4.: Comparison of segments of figure 4.2 from $6 \mathrm{~s}$ to $9.5 \mathrm{~s}$ TWT 


\subsection{Data regularization}

The regularization process implemented in the partial CRS algorithm, is based on the interpolation process over the partial CRS stack aperture. This process can be seen as an automated interpolation at every regular offset interval. In figure 4.5 the regularized supergather is presented with an offset of $4000 \mathrm{~m}$. The number of traces in the supergather is highly increased in comparison to the original data record (cf. figure 4.1). The close-up of the data included in figure 4.5 shows a data window from $0 \mathrm{~m}$ to $500 \mathrm{~m}$ offset and $3.75 \mathrm{~s}$ to $5.25 \mathrm{~s}$ TWT. Particularly, in the close-up one can see the equal spacing between the traces. Furthermore, it becomes evident that the $\mathrm{ZO}$ trace is included in the supergather. The intervals were chosen at $75 \mathrm{ft}$ or $22.86 \mathrm{~m}$, which is the original receiver spacing of the Sigsbee $2 \mathrm{~A}$ data record. I chose a decimal spacing in the metric system to evaluate the accuracy of the regularization process.

The advantages resulting from these precise spacings are the regularization of varying trace spacings due to acquisition errors, the possibility to convert unit systems of acquired data, i.e. from imperial to metric system and the increase of traces contributing to consecutive processing. Additionally, figure 4.5 shows the low noise-level of the regularized supergather due to the CRS stacking process.

\subsection{Extrapolation}

The extrapolation process creates traces beyond the physical offset of the acquisition setup. These traces constitute an additional contribution to the total quantity of traces to further processing. Physical boundaries set a limit to the possibilities of extrapolation, because the partial CRS apertures have a close relation to the Fresnel zone in the underground. Extrapolation over the limit of the Fresnel zone bears the risk of extrapolation artifacts such as signal changes or artifacts that will disturb stacking processes. Traces calculated beyond the limits of the Fresnel zone are calculated on the base of data, which has already been extrapolated and will lead to ampltude artifacts such as escalation and signal splitting. In figure 4.7 I chose the partial CRS apertures exceeding the Fresnel zone by more than the factor of two and the offset to range from $3299 \mathrm{~m}$ to $4799 \mathrm{~m}$, intentionally breaching the physical limitations. This offset includes an interpolated part of the supergather from $3299 \mathrm{~m}$ to $4000 \mathrm{~m}$. Traces from $4001 \mathrm{~m}$ to $4799 \mathrm{~m}$ offset show the extrapolation from the original data. 


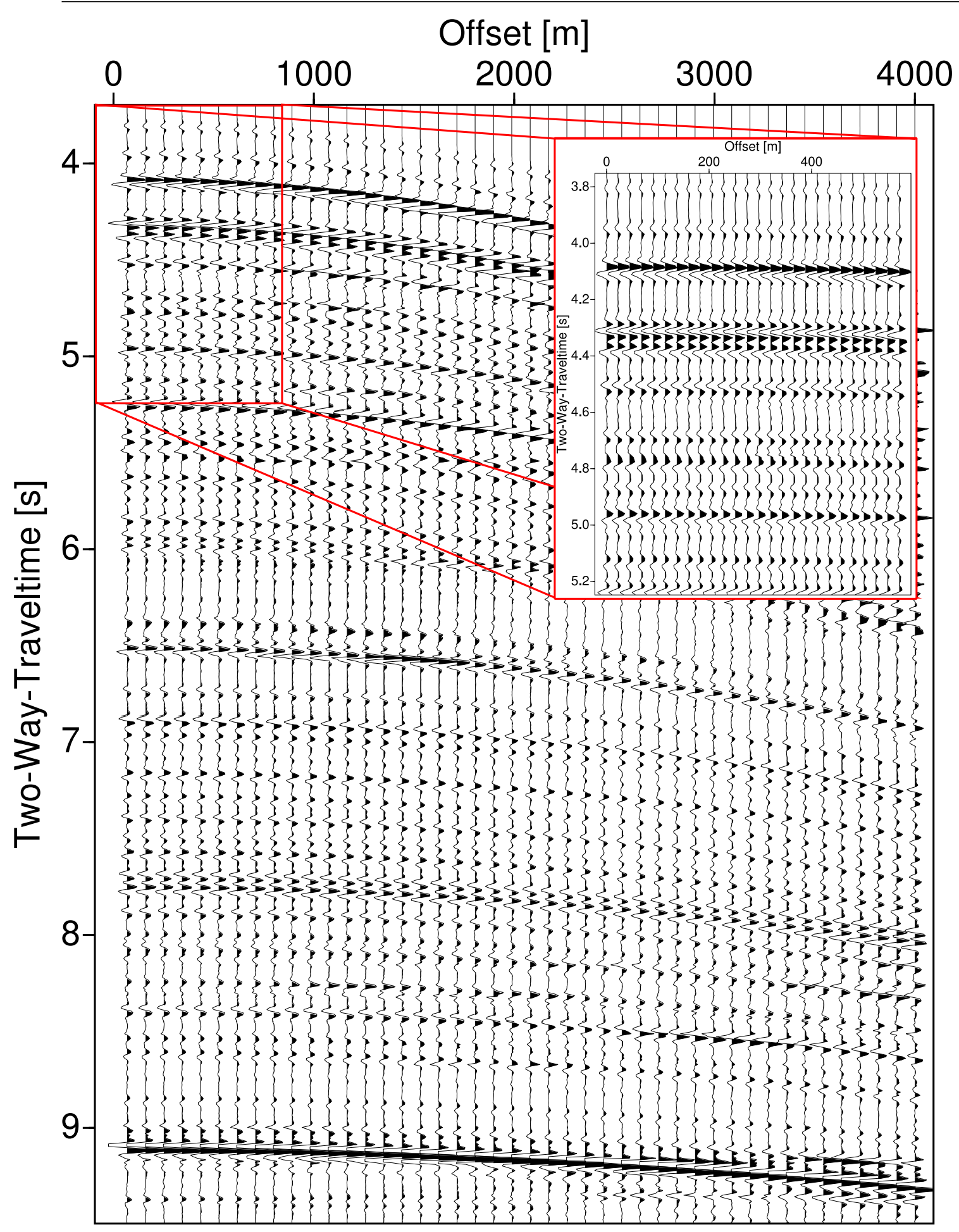

Figure 4.5.: Regularized data with close-up from $0 \mathrm{~m}$ to $500 \mathrm{~m}$ offset and $3.75 \mathrm{~s}$ to $5.25 \mathrm{~s}$ TWT 


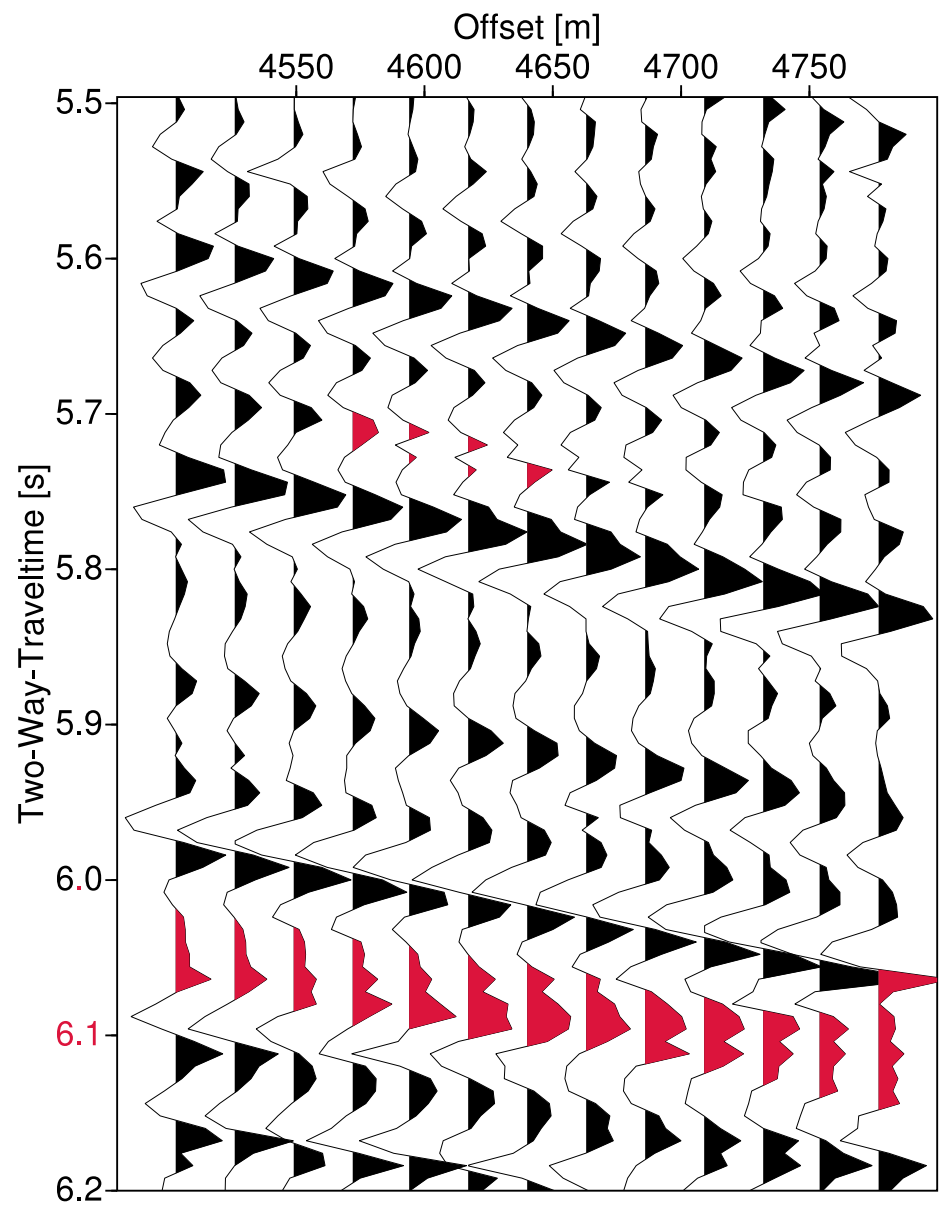

Figure 4.6.: Close-up of extrapolated data from $4500 \mathrm{~m}$ to $4799 \mathrm{~m}$ offset
The data starts at 4s TWT because the direct wave is not to be considered in the evaluation of the extrapolation process, because on the analogy of the interpolation process in section 4.1 , the linear direct wave can neither be interpolated nor extrapolated by the hyperbolic CRS approach.

The image yields a reasonable result. The move-out, as well as the arrival times of the traces within a highly fitted range and the reflection events from the interpolated part in the supergather are continued flawlessly. The first two major reflection events are continuous over the entire offset, whereas the smaller amplitudes at 5s TWT smear for an offset greater than $4400 \mathrm{~m}$. The packet of reflections from $5.1 \mathrm{~s}$ to $6.3 \mathrm{~s}$ TWT is continuous to the offset of $4400 \mathrm{~m}$. Beyond that offset some variations occur because the physical limitations have been exceeded.

In figure $4.6 \mathrm{I}$ zoomed in on this part of the extrapolation. It can be observed, that the major reflection events at 5.6s, 5.74s and 5.97s TWT stay discrete and continuous. However, the amplitudes increase proportional to increasing offset. Splitting of the signal can be seen at $5.7 \mathrm{~s}$ TWT in the traces at $4595 \mathrm{~m}$ up to $4685 \mathrm{~m}$ offset. Another effect contributing to the spotty image is the smearing of amplitudes, which can be seen in the reflection events at $5.87 \mathrm{~s}, 5.92 \mathrm{~s}$ and especially $6.05 \mathrm{~s}$ TWT. The reflection event at $6.05 \mathrm{~s}$ TWT smears, so that it links to the major reflection event prior to it. 


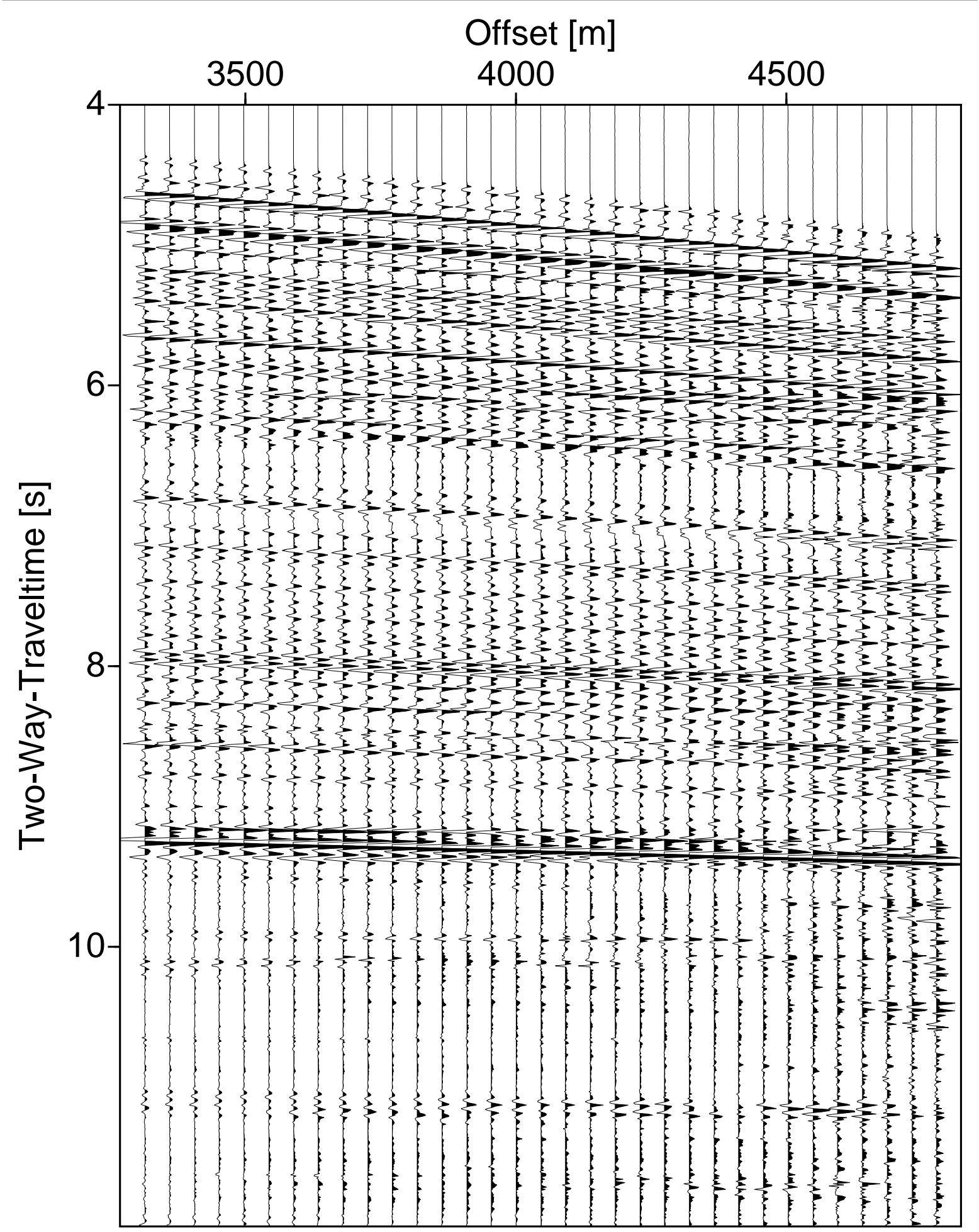

Figure 4.7.: Comparison of far-offset to extrapolation with an offset of $3299 \mathrm{~m}$ to $4799 \mathrm{~m}$ 


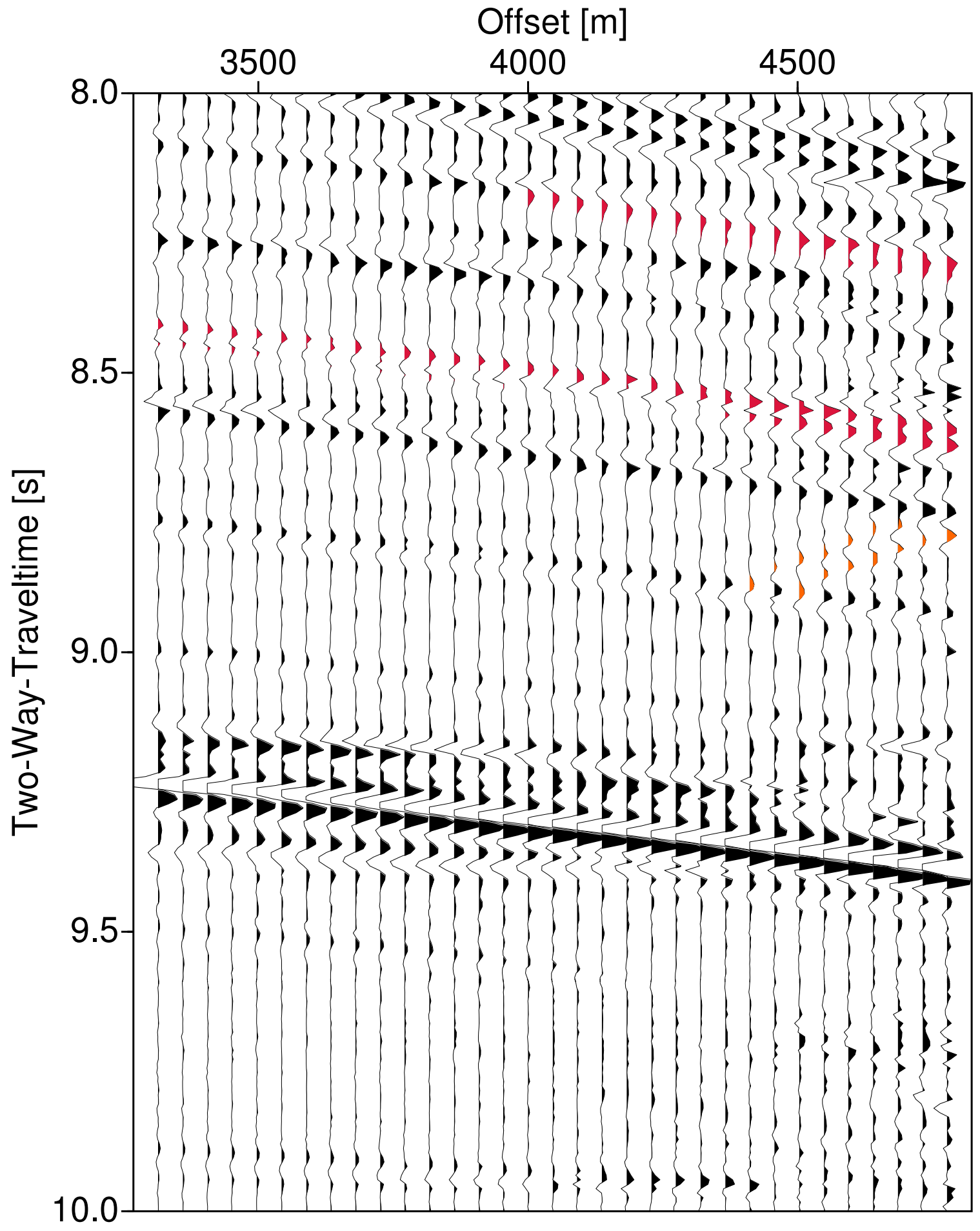

Figure 4.8.: Extrapolation artifacts in close-upfrom $3299 \mathrm{~m}$ to $4799 \mathrm{~m}$ offset and 8 s to 10 s TWT 
These might be ordinary amplitude fluctuations, which become visible once a seismic gather is examined close enough. For this reason, I present another close up of the extrapolated gather in figure 4.8. It is a temporal window from 8.0s to 10.0s TWT over the offset presented in figure 4.5. The window in figure 4.8 was chosen to demonstrate extrapolation artifacts in succession to an over-sized partial CRS aperture.

As a result of exceeding the physical limitations amplitude artifacts appear. Two effects were marked red in figure 4.8. Starting at 8.1s TWT reflections smear at an offset greater than $4500 \mathrm{~m}$. The event starting at $8.4 \mathrm{~s}$ TWT shows how amplitudes appear from tiny reflections, so called escalation. Another amplitude artifact was marked orange and starts at $8.6 \mathrm{~s}$ TWT and $4500 \mathrm{~m}$. At an upward angle of $30^{\circ}$ two apparent reflection events dissolve from the actual reflection, creating a geometry reminiscent of a Mach cone. Further artifacts can be seen in the entire zone, where the physical limitations has been exceeded. They would corrupt further processing steps and therefore, the processor must not breach stability criteria provided by the first Fresnel zone.

The extrapolation within the Fresnel zone is as promising as the interpolation process. Once we expand the partial CRS apertures it becomes more likely that unwanted artifacts are produced. This may create misleading information in the supergather, which should be avoided by any means. Amplification and smearing of amplitudes will distort the results of further processing. 


\section{Conclusion and Outlook}

I provide this chapter to evaluate data presented in chapter 4 to answer the central questions raised in the introduction in chapter 1 . Accordingly, I will analyze the results of the interpolation, regularization and extrapolation in section 4.1 to 4.3 .

The interpolation process of the partial CRS presented in section 4.1 has shown promising results. The arrival times of the interpolated gather coincide with the original gather within minimum numerical tolerance. The major reflection events were interpolated very well, while minor reflection events have been tapered compared to the original amplitudes. The amplitudes were preserved very well on first examination. Amplitude picking is appropriate to back this observation but that would break the mold of this thesis. The frequencies also are preserved very accurate. Albeit, some low-amplitude noise was introduced to the frequency band of some traces. Another drawback lies within the interpolation of the direct wave. The linear move-out cannot be handled by the hyperbolic approach of the partial CRS stack, leaving the interpolation results of the direct wave to be incorrect and misleading. In the course of this thesis, I have found that overly sparse data with gaps exceeding the first Fresnel zone and therefore, breaching stability criteria bears interpolation errors.

A special interest in interpolation of near-offset traces was investigated and shown to be particularly accurate.

The data regularization, using the trace interpolation on equal spacings, was validated by the results of the interpolation process presented beforehand. The regularization process can be set to any offset desired.

The extrapolation process of section 4.3 has shown to be a complex task because numerous factors that have to be taken into account. The processor must not exceed the partial 
CRS stacking apertures larger than the Fresnel zone in the subsurface, breaching physical limitations. This breach results in amplitude artifacts and possible signal changes. For this model extrapolation above the first Fresnel zone to some extent has shown unexpectedly good results. This observation is not valid for every model and erroneous traces will be produced, when stability criteria are breached. However, extrapolation within the limits of the Fresnel zone shows to contribute valuable traces to the gather that possess the accuracy of the interpolation process.

In future research the results of interpolation, regularization and extrapolation will be examined for field data. In this thesis I would have liked to closer examine amplitude preservation as well as physical limitations of the interpolation process. However, this would have broken the mold of a bachelor thesis, leaving possibilities to future research.

On the behalf of pre-stack data enhancement the results of these surveys should be repeated with increased SNR. Examining the limits of this process, as well as finding the maximum offset gap in sparse data that can be interpolated might be a task for future research.

Moreover, it would be interesting to compare the interpolation process of the partial CRS stack to trace interpolation of waveform-based algorithms in f-x (cf. Spitz [1991], Naghizadeh and Sacchi [2009]) or f-k domain (cf. Pann and Fields [1986]). 


\section{A. Acknowledgements}

I am truly grateful to Prof. Dr. Dirk Gajewski for welcoming me to the applied seismic working group and entrusting me with this ambitious bachelor thesis. The promotion of young researchers and his support and constant interest always kept me motivated to keep learning and create these results.

A thousand thanks to Dr. Claudia Vanelle, who always had an open door for any problem concerning my work or my studies. Many thanks for always keeping the machinery going and making things work in the university.

In addition, I want to thank Christian Hübscher and Ekkehart Tessmer, who lay the foundation to my geophysical education and were always supportive, when I had some questions.

I appreciate Sergius Dell always helping me with the CRS software and introducing me to partial CRS stacks. Moreover, I would like to thank my fellow studen Robert Pfau who was always open for discussion, regarding CRS stacks. Their assistance was a great convenience during my studies. Many thanks go to Dr. Mikhail Baykulov and Dr. Jürgen Mann who lay the foundation to my thesis.

I gratefully appreciate the constant interest of Prof. Dr. Wolfgang Kowalk in my education and studies. The fruitful discussions and helpful financial support helped me do my way in university.

The support of my girlfriend and companion Anna Schulz were a blessing. She always kept patience, when none was expected and had some great advice concerning this thesis.

I thank Patrick Püttschneider for the discussions from a different point of view. He was able to clear things up, when I was just to close to see.

I graciously acknowledge the Univerity of Hamburg and the WIT consortium for their ongoing financial support and the SMAART JV for the Sigsbee2A data record. 


\section{Selbstständigkeitserklärung}

Hiermit bestätige ich, dass die vorliegende Arbeit von mir selbständig verfasst wurde und ich keine anderen als die angegebenen Hilfsmittel - insbesondere keine im Quellenverzeichnis nicht benannten Internet-Quellen - benutzt habe und die

Arbeit von mir vorher nicht in einem anderen Prüfungsverfahren eingereicht wurde. Die eingereichte schriftliche Fassung entspricht der auf dem elektronischen Speichermedium.

Ich bin damit einverstanden, dass die Bachelorarbeit veröffentlicht wird.

(Jesper S. Dramsch) 


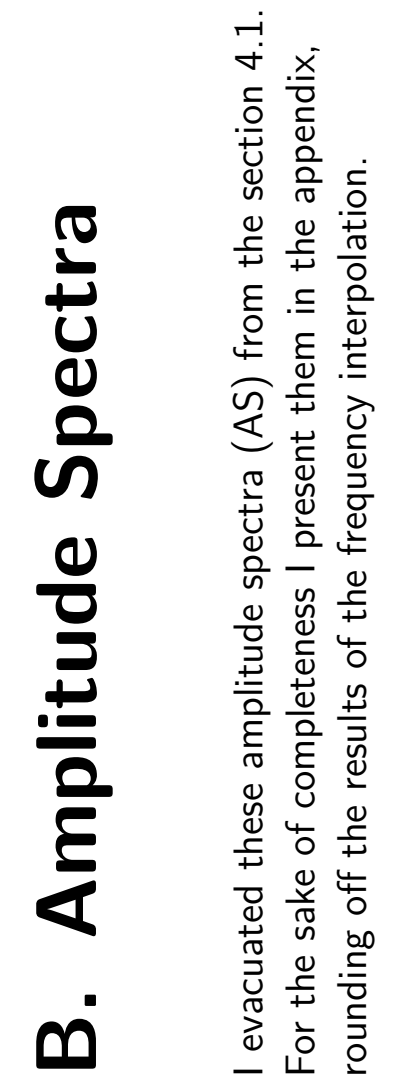



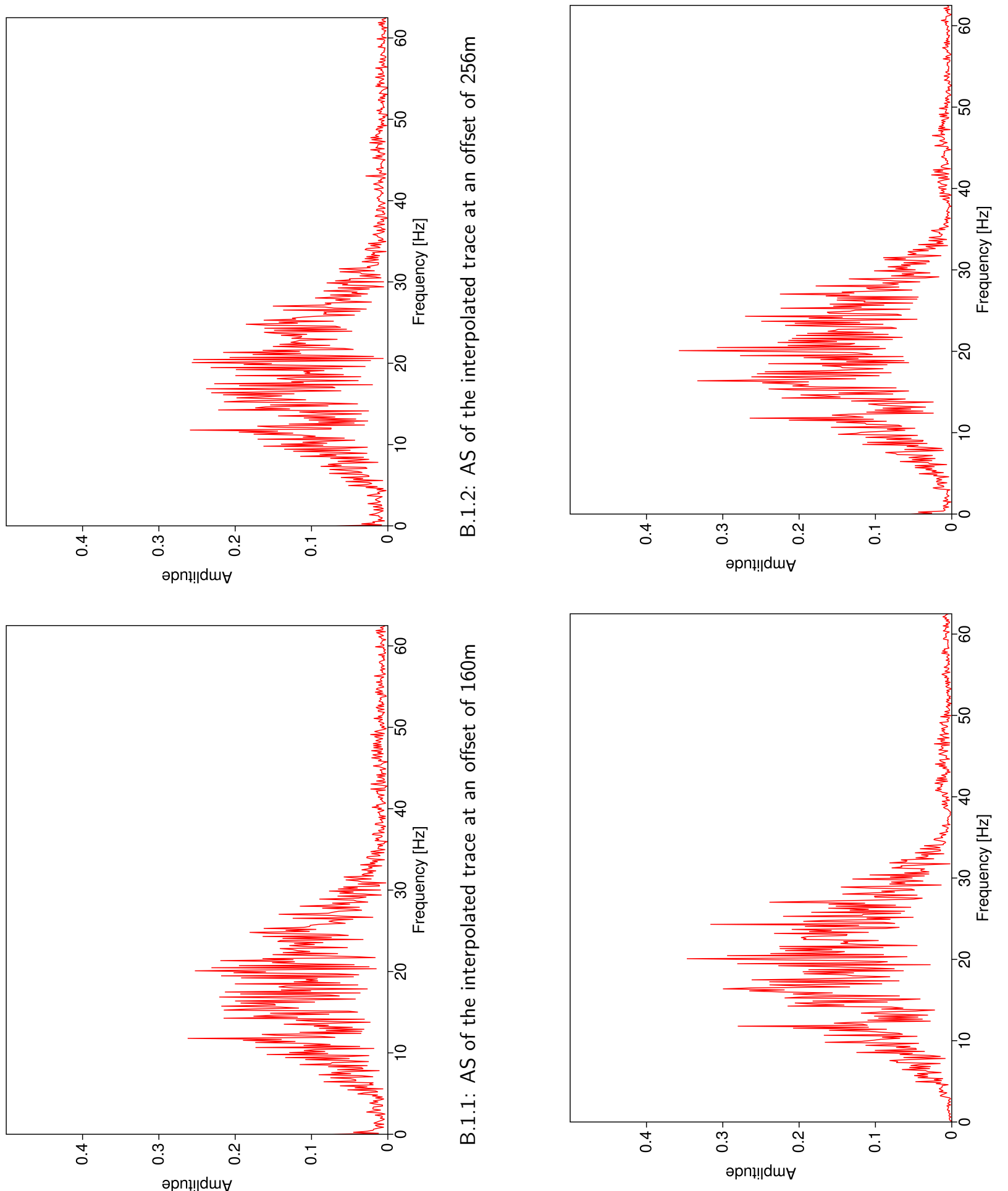

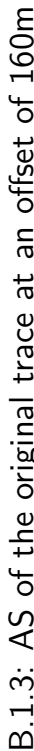

IV 

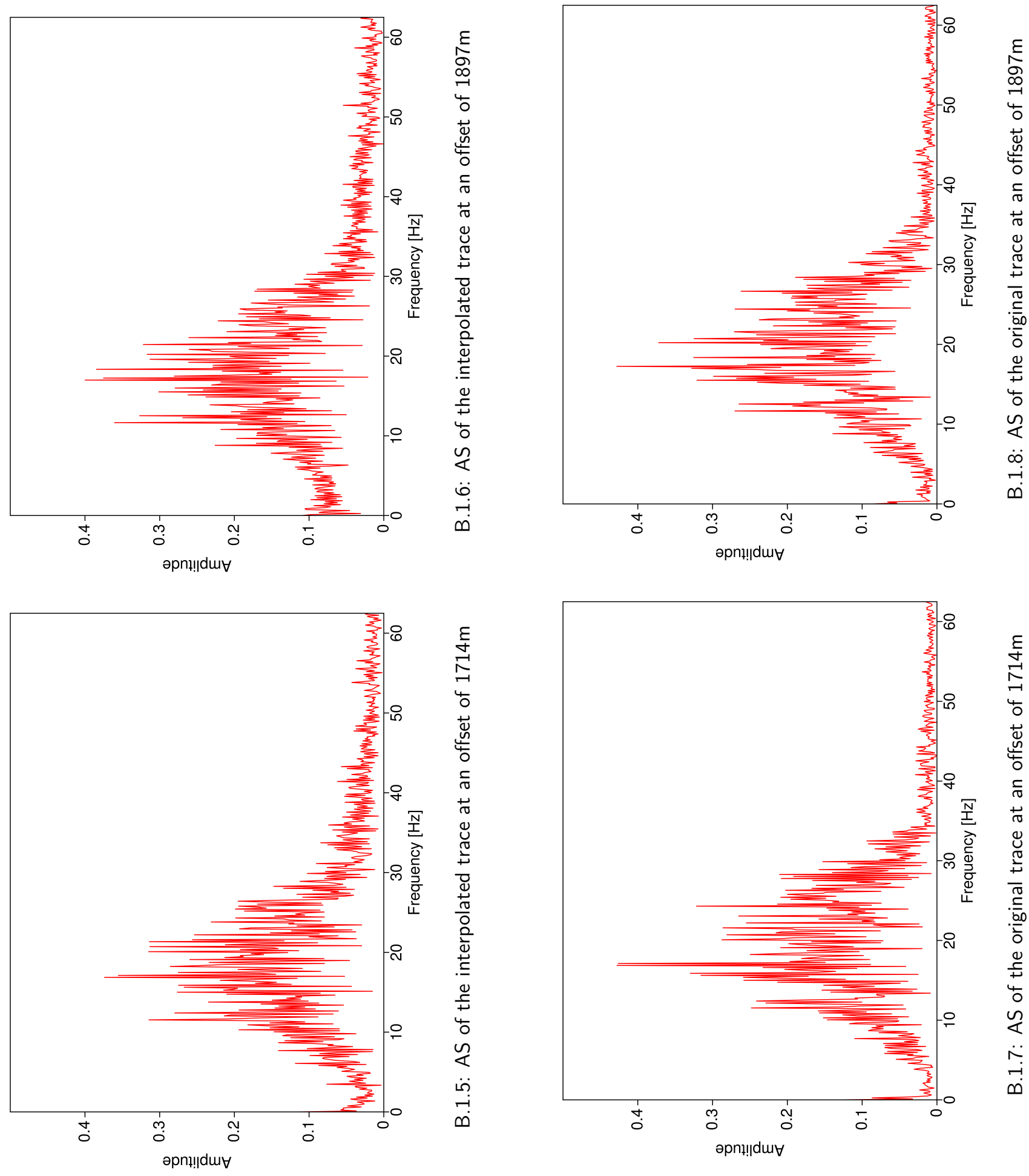


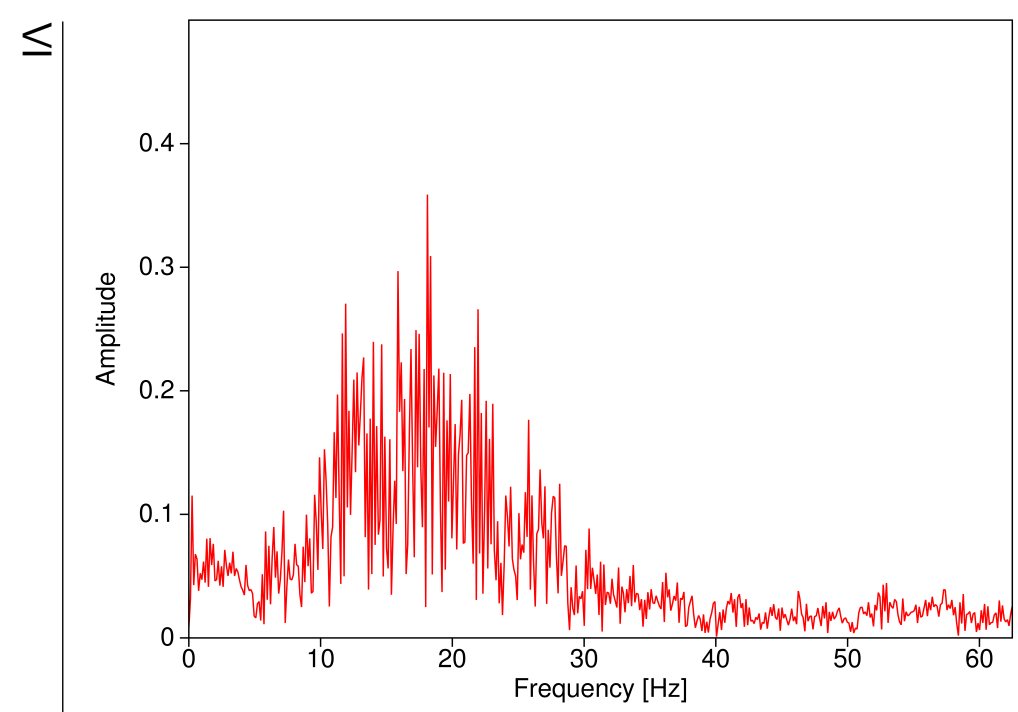

B.1.9: AS of the interpolated trace at an offset of $2994 \mathrm{~m}$

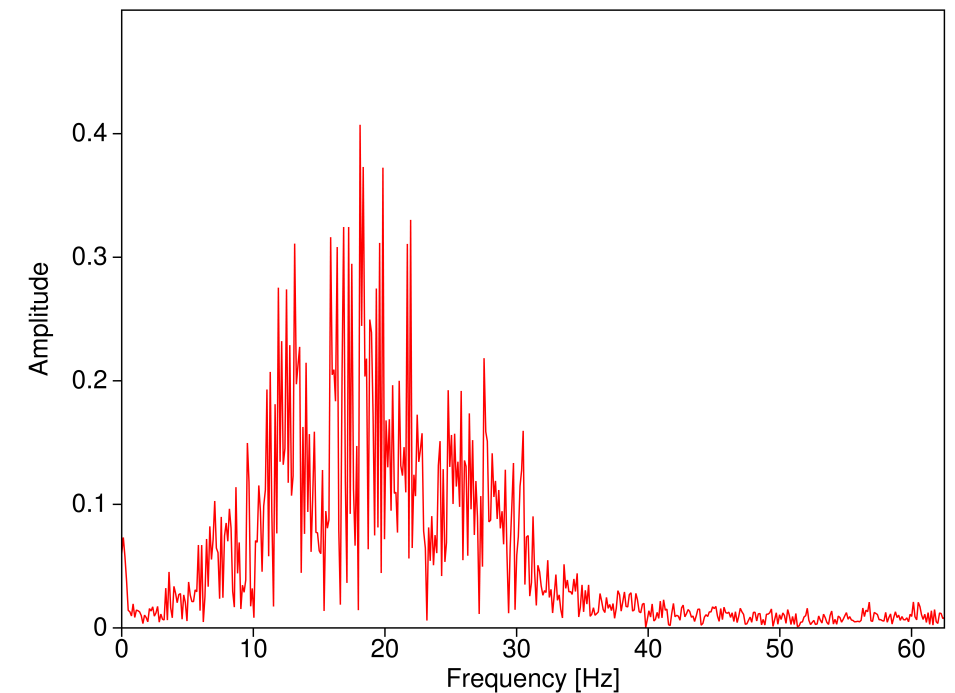

B.1.11: AS of the original trace at an offset of $2994 \mathrm{~m}$

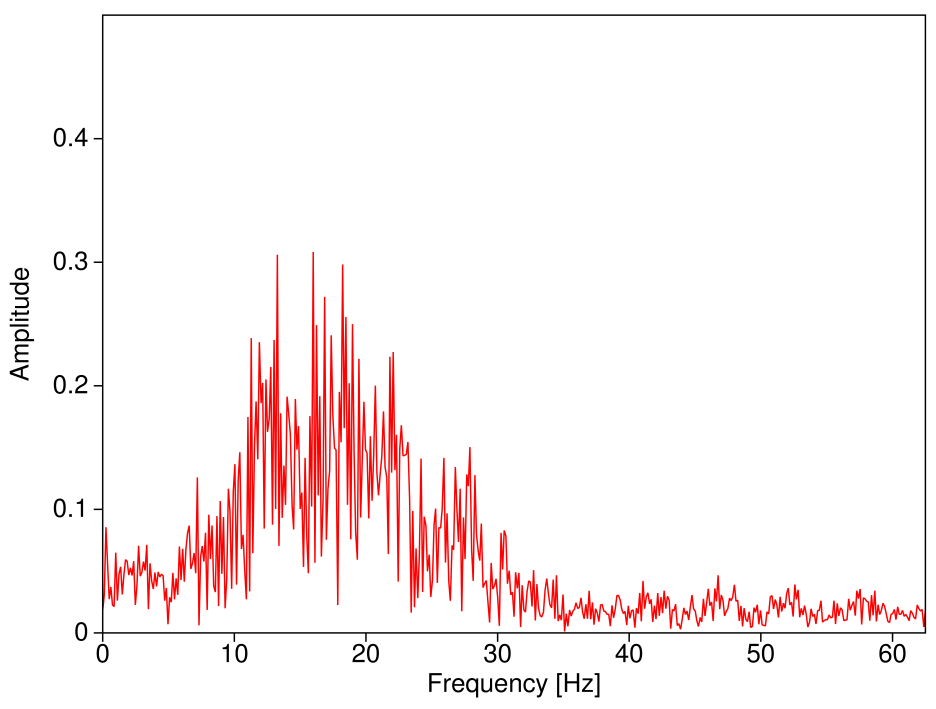

B.1.10: AS of the interpolated trace at an offset of $3086 \mathrm{~m}$

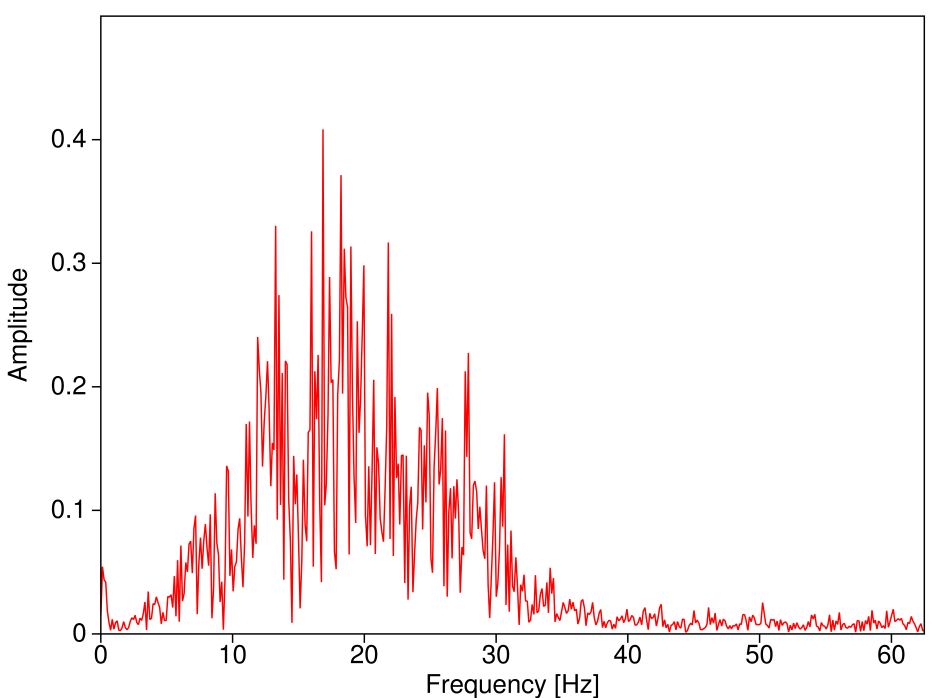

B.1.12: AS of the original trace at an offset of $3086 \mathrm{~m}$ 


\section{Bibliography}

Baykulov, M. (2008). Partial CRS stack User's Manual.

Baykulov, M. (2009). Seismic imaging in complex media with the Common Reflection Surface stack. PhD thesis, Universität Hamburg.

Baykulov, M. and Gajewski, D. (2009). Prestack seismic data enhancement with partial common reflection surface (crs) stack. Geophysics, 74:49 - 58 .

Dümmong, S. (2006). Alternative implementation des common reflection surface stapelverfahrens. Master's thesis, Universität Hamburg.

Dümmong, S., Baykulov, M., and Gajewski, D. (2009). A workflow for the processing of reflection seismic data with crs attributes. SEG, Expanded Abstracts,, 28:3173-3177.

Gajewski, D. (2010). Vorlesungsskript angewandte geophysik 2. Kompiliert von Christina Raub und Anja Lindenthal.

Mann, D. J. (2002). Extensions and Applications of the Common-Reflection-Surface Stack Method. PhD thesis, Universität Karlsruhe (TH).

Mann, D. J. (2003). 2-D zero-offset Common-Reflection-Surface Stack User's Manual. Universität Karlsruhe $(\mathrm{TH})$.

Müller, T. (1999). The Common Reflection Surface Stack Method - Seismic imaging without explicit knowledge of te velocity model. PhD thesis, Universität Karlsruhe (TH).

Naghizadeh, M. and Sacchi, M. (2009). F-x adaptive seismic-trace interpolation. Geophysics, 74:9-16.

Pann, K. and Fields, J. L. (1986). Seismic trace interpolation using f-k filtering.

Spitz, S. (1991). Seismic trace interpolation in the f-x domain. Geophysics, 56:785-796.

Verschuur, D. J., Berkhout, A. J., and Wapenaar, C. P. A. (1992). Adaptive surface-related multiple elimination. Geophysics, 57:1166-1177. 
Yilmaz, O. (2001). Seismic data analysis : processing, inversion, and interpretation of seismic data. Society of Exploration Geophysicists. 


\section{List of Figures}

2.1. The CRS stacking surface approximates the curvature of the reflector in the underground in midpoint displacement, half-offset and time domain. (cf. Baykulov [2009]) . . . . . . . . . . . . . . . . . . . . . . . . . . . . . 6

2.2. Visualize the CRS parameters introduced in section 2.1 (from Müller [1999], edited) . . . . . . . . . . . . . . . . . . . . . 7

3.1. CMP 200 of original data record. Red traces mark data gaps in the sparse data record.

4.1. Supergather consisting of data that was interpolated, regularized and extrapolated. . . . . . . . . . . . . . . . . . . . . . . 12

4.2. Comparison of the interpolated and the original traces . . . . . . . . . . . 14

4.2.1. Original traces in CMP $200 \ldots \ldots$. . . . . . . . . . . . . . . 14

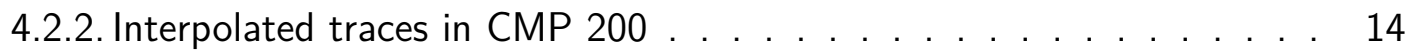

4.3. Interpolated and original amplitude spectra of two traces at the offset of $68 \mathrm{~m}$ in near offset and $1805 \mathrm{~m}$ in mid-offset (cf. appendix B for spectra of all interpolated traces) . . . . . . . . . . . . . . . . . . . 16

4.3.1. Amplitude spectrum of the interpolated trace at an offset of $68 \mathrm{~m} \ldots \ldots \ldots 16$

4.3.2. Amplitude spectrum of the interpolated trace at an offset of $1805 \mathrm{~m} \ldots \ldots$. . . . . . . . . . . . . 16

4.3.3. Amplitude spectrum of the original trace at an offset of $68 \mathrm{~m} \ldots \ldots . \ldots 16$

4.3.4. Amplitude spectrum of the original trace at an offset of $1805 \mathrm{~m} \ldots \ldots \ldots 16$

4.4. Comparison of segments of figure 4.2 from 6 s to 9.5 s TWT . . . . . . . . . 18

4.4.1. Segment of original near-offset data . . . . . . . . . . . . . . 18

4.4.2. Segment of interpolated near-offset data . . . . . . . . . . . . . . . 18 
4.5. Regularized data with close-up from $0 \mathrm{~m}$ to $500 \mathrm{~m}$ offset and $3.75 \mathrm{~s}$ to $5.25 \mathrm{~s}$ TWT . . . . . . . . . . . . . . . . . . 20

4.6. Close-up of extrapolated data from $4500 \mathrm{~m}$ to $4799 \mathrm{~m}$ offset . . . . . . . . . 21

4.7. Comparison of far-offset to extrapolation with an offset of $3299 \mathrm{~m}$ to $4799 \mathrm{~m}$. 22

4.8. Extrapolation artifacts in close-up of extrapolated data from $3299 \mathrm{~m}$ to $4799 \mathrm{~m}$ offset and 8 s to 10 s TWT . . . . . . . . . . . . . . . . . 23 